\title{
Assessment of effectiveness and safety of Ibicella lutea extract in the control of experimental Proteus mirabilis urinary tract infection
}

\author{
Vanessa Sosa and Pablo Zunino \\ Departamento de Microbiología, Instituto de Investigaciones Biológicas Clemente Estable (IIBCE), Avenida Italia \\ 3318, Montevideo, Uruguay
}

\begin{abstract}
Introduction: Proteus mirabilis is an important cause of complicated urinary tract infections (UTI). Like many other microorganisms, $P$. mirabilis has acquired resistance to many antibiotics. Due to the serious effects associated with uropathogenic $P$. mirabilis and the problems related to the use of antibiotics, alternative strategies for its control must be developed. Previously, we studied the effect of Ibicella lutea extract, a South American indigenous plant, on in vitro uropathogenicity of P. mirabilis. We observed that I. lutea extract had an effect on various attributes associated with $P$. mirabilis urovirulence. The objective of this study was to assess $I$. lutea extract against UTI by $P$. mirabilis.

Methodology: This study was based on the effect of $I$. lutea extract to prevent or treat $P$. mirabilis experimental UTI in mice and the influence of this administration on the normal intestinal flora. Also, we studied the toxicity, mutagenicity, and antimutagenicity of the extract. Results: In this study, while I. lutea administration showed an effect in the prevention and treatment of UTI in the mouse, the intestinal microflora did not change. The I. lutea extract was neither toxic nor mutagenic although the extract showed antimutagenic properties.

Conclusion: These findings suggest that the administration of I. lutea extract could represent an interesting new strategy to control $P$. mirabilis UTI.
\end{abstract}

Key words: urinary tract infection, Proteus mirabilis, Ibicella lutea, toxicity, mutagenicity.

J Infect Dev Ctries 2010; 4(12):814-821.

(Received 26 April 2010 - Accepted 29 July 2010)

Copyright ( 92010 Sosa and Zunino. This is an open-access article distributed under the Creative Commons Attribution License, which permits unrestricted use, distribution, and reproduction in any medium, provided the original work is properly cited.

\section{Introduction}

Urinary tract infections (UTI) are among the most common infections in humans and represent the most frequent urologic disease affecting the bladder and kidneys [1]. Proteus mirabilis, a motile Gramnegative bacterium, is one of the principal cause of UTI in catheterized patients and those with urinary tract abnormalities. Individuals suffering from UTI caused by $P$. mirabilis often develop bacteriuria, cystitis, kidney and bladder stones, catheter obstruction due to stone encrustation, acute pyelonephritis, and fever [2].

The preventive therapeutics in UTI include the use of antibiotic treatments. Antibiotic-resistant bacterial strains are increasingly detected and thus new drugs are required [3]. Finding new antimicrobial agents with novel mechanisms is essential and extensively pursued in antibacterial drug discovery [4]. Natural products are still important as a source of great potential for drug discovery. Plants have been the largest natural source of new drugs, though only less than $5 \%$ of known plants have been chemically characterized. Extracts from plants can have significant value in antimicrobial research as they may inhibit bacterial growth by different mechanisms or interfere with different bacterial virulence attributes.

In a previous work, we studied the extract of Ibicella lutea, a South American indigenous plant, and its effect on growth, virulence, and biofilm formation of uropathogenic $P$. mirabilis [5]. We observed that I. lutea extract had an effect on bacterial growth rate, bacterial morphology, swarming differentiation, hemagglutination, and biofilm formation on glass and polystyrene. These findings suggest that I. lutea may have a role as an agent for the prevention or treatment of $P$. mirabilis UTI.

In general, in vitro results cannot be simply extrapolated to in vivo conditions for antimicrobial drugs [6]; therefore, data generated from both systems are necessary and irreplaceable. 
Due to the lack of knowledge concerning potential toxicity and adequate usage, medicinal herbs are often incorrectly used, thereby not yielding the desired effect. Consequently, when a possible new antimicrobial agent is found, the next logical step is to assess its safety. The identification of chemicals or compounds capable of inducing mutations is crucial in safety assessment since mutagenic compounds can potentially induce cancer [7].

In this study, and based on our previous encouraging results, we examined the potential role of I. lutea extract to treat and prevent $P$. mirabilis experimental UTI in an animal model and the influence of this administration on the normal intestinal flora. We also studied toxicity, mutagenicity, and antimutagenicity of the crude chloroform extract of the aerial parts of I. lutea using different approaches.

\section{Methodology}

Bacterial strain, media and growth conditions

P. mirabilis strain Pr2921 was isolated from a symptomatic UTI of an adult woman (Montevideo, Uruguay) [8]. Pr2921 was stored at $-80^{\circ} \mathrm{C}$ in LuriaBertani (LB) broth supplemented with $12 \%(\mathrm{v} / \mathrm{v})$ glycerol and grown aerobically at $37^{\circ} \mathrm{C}$. One mutant strain, Salmonella enterica serovar Typhimurium ( $S$. Typhimurium) strain TA98 (his D3052, rfa, uvrB, pKM101) [9], was used in the Ames test. This strain was maintained on nutrient agar at $3^{\circ} \mathrm{C} \pm 1^{\circ} \mathrm{C}$. The bacteria were inoculated in nutrient broth $(\mathrm{NB})$ and incubated at $37^{\circ} \mathrm{C}$ for 18 to 24 hours before performing the test.

All media were from Difco Laboratories (Detroit, MI, USA) and all chemicals were reagent grade (Sigma Chemical, Milwaukee, WI, USA).

All in vitro assays were performed in media supplemented with I. lutea extract as indicated in each assay and in media without vegetal extract but containing water/ethanol (70:30, control).

\section{Plant material}

I. lutea was collected from Canelones, Uruguay, and identified by Mario Piaggio in the Botanic Garden of Montevideo (Government of Montevideo, Uruguay). A voucher specimen was deposited in the herbarium of the Botanic Garden bearing the number MVJB 26512.

The extract had been previously produced for in vitro studies reported in our previous work [5]. Aerial parts of I. lutea $(1000 \mathrm{~g})$ were air-dried in the dark.
Once dried, the plant material was ground, extracted by maceration for 48 hours with $\mathrm{CHCl}_{3}$, and the solvent was vacuum evaporated (oil obtained, $21 \mathrm{~g}$ ). Then solutions were prepared in $30 \%(\mathrm{v} / \mathrm{v})$ aqueous ethanol and further dilutions were made in the same solvent to obtain the required extract concentrations for the different assays.

\section{UTI model in the mouse}

Two-month-old female CD-1 mice weighing about $20 \mathrm{~g}$ were used. The animals were provided with food pellets and tap water ad libitum and their environmental conditions were kept constant. To assess the potential preventive or therapeutic effect of I. lutea extract, a well-established ascending UTI model in the mouse was used $[8,10]$. This experiment was conducted in accordance with procedures authorized by IIBCE, Montevideo, Uruguay. Briefly, bacteria for these assays were grown at $37^{\circ} \mathrm{C}$ for 48 hours in LB broth. Prior to transurethral challenge, mice had been anesthesized with xylazine $(10 \mathrm{mg} / \mathrm{kg})$ and ketamine $(50 \mathrm{mg} / \mathrm{kg})$, and their bladders were emptied by gentle abdominal massage. Using this technique, mice were anesthetized for approximately 40 minutes. A sterile $25 \mathrm{~mm}$ long soft polyethylene catheter (outer diameter $0.61 \mathrm{~mm}$ ) was gently inserted into the bladder through the urethra. A 30 gauge needle attached to a tuberculin syringe containing the Pr2921 bacterial suspension $\left(10^{8}\right.$ colony-forming units $(\mathrm{CFU}) / \mathrm{mL}$ ) was inserted into the catheter lumen and $0.05 \mathrm{~mL}$ of the bacterial suspension was infused into the bladder over 30 seconds to avoid vesicouretheral reflux. The catheter was removed immediately after the mouse challenge and the experimental mice were housed in conventional plastic cages. The mice were euthanized by cervical dislocation at seven days after transurethral challenge, and the bladder and kidneys of each animal were removed and homogenized in 10 $\mathrm{mL}$ of PBS using a Stomacher 80 Lab Blender (Seward, Worthing, UK). Viable bacterial counts were done on $\mathrm{LB}$ with $2 \%$ agar and without $\mathrm{NaCl}$ to avoid swarming motility.

\section{Preventive assays}

One group of ten mice was daily orally administered with of $I$. lutea extract $(100 \mu \mathrm{L}, 0.2$ $\mathrm{mg} /$ mouse) by gavage. Another group of ten animals was treated in the same way with $100 \mu \mathrm{L}$ of the vehicle of the I. lutea extract ( $30 \%$ ethanol). Both groups of mice were then transurethrally challenged with Pr2921 three days upon the initial treatment and 
subsequently killed by cervical dislocation seven days after the challenge with $P$. mirabilis Pr2921.

\section{Therapeutic assays}

Three groups of 12 mice were challenged via the transurethral route with Pr2921. Five hours after the challenge, two groups of mice were orally treated with $100 \mu \mathrm{L}$ of $I$. lutea extract $(0.2$ and 0.5 $\mathrm{mg} /$ mouse) while the third group was treated with $30 \%$ ethanol only.

Animals were treated daily with I. lutea extract or $30 \%$ ethanol for five days, and killed by cervical dislocation seven days after the challenge.

\section{Influence of I. lutea extract administration on the normal feacal flora}

Qualitative and quantitative analysis of the faecal flora was performed by bacterial counts using fresh stools [11]. Briefly, dilutions of stools in PBS were inoculated on the following agar media: blood agar for total aerobes and anaerobes, MacConkey's agar for detection of Enterobacteriaceaeae, and MRS agar for lactic acid bacteria (LAB) (Difco Laboratories, Detroit, MI, USA). Aerobic cultures were incubated at $37^{\circ} \mathrm{C}$ for 72 hours. Media for anaerobic bacteria were incubated at $37^{\circ} \mathrm{C}$ in an anaerobic chamber up to five days. The number of bacteria was expressed as $\log _{10} \mathrm{CFU} / \mathrm{g}$ of stools.

\section{Brine shrimp lethality bioassay}

Artemia salina eggs were incubated in artificial seawater $\left(3.6 \mathrm{~g} \mathrm{NaCl}, 1.5 \mathrm{~g} \mathrm{Mg}_{2} \mathrm{SO}_{4}, 0.5 \mathrm{~g} \mathrm{NaHCO}_{3}\right.$ in $100 \mathrm{~mL}$ distilled water, $\mathrm{pH}$ 9) at $28^{\circ} \mathrm{C}$ under tungsten light. After incubation for 24 hours, nauplii were collected with a Pasteur pipette. The I. lutea extract (triplicate) was serially diluted $(0.5,1,2,5$, and 10 $\mathrm{mg} / \mathrm{mL}$ ) in artificial seawater. Between $10 \pm 2$ nauplii were added to each set of microwells containing the samples and the cultures were further incubated at $28^{\circ} \mathrm{C}$ for 24 hours [12]. Controls containing 30\% ethanol (negative control) and containing potassium dichromate $\left(\mathrm{K}_{2} \mathrm{Cr}_{2} \mathrm{O}_{4}\right.$, positive control) were included on each set of experiments.

Percentage of mortality was calculated according to the following formula: $\mathrm{M}_{\mathrm{mct}}=\left(\mathrm{N}_{\mathrm{Mm}} / \mathrm{N}_{0}\right) * 100$, where: $\mathrm{M}_{\mathrm{mct}}$ is mortality of individuals in time $t, \mathrm{~N}_{\mathrm{Mm}}$ is average number of dead individuals, and $\mathrm{N}_{0}$ is initial number of living individuals at the test start.

\section{Ames test}

In the Ames test, $S$. Typhimurium TA98 was genotyped according to Maron and Ames [9] to ensure the purity of the strain.

\section{Toxicity assay}

To examine the toxic effects on $S$. Typhimurium TA98, a diluted I. lutea extract $\left(1 \times 10^{-5}-2 \times 10^{-5} \mathrm{mg}\right)$ was added to overnight-cultured $S$. Typhimurium TA98 $(0.1 \mathrm{~mL})$. The mixture was preincubated at $37^{\circ} \mathrm{C}$ for five minutes before it was diluted with phosphate buffer, and the mixture was then poured onto NA plates. The plates were incubated at $37^{\circ} \mathrm{C}$ for two days, and the number of colonies was counted [13]. The I. lutea extract was then tested for its mutagenic/antimutagenic potency exclusively in the nontoxic concentration range.

\section{Mutagenicity assay}

The mutagenic effect of I. lutea extract was assayed according to the Ames test using $S$. Typhimurium TA98 [9]. The tested strain was cultured overnight in NB for 12 hours. Different concentrations of $I$. lutea extract $(0.5,1$, and 2 $\mathrm{mg} / \mathrm{plate}$ ) were added to $2 \mathrm{~mL}$ of top agar and $0.1 \mathrm{~mL}$ of bacterial culture and then poured onto a plate containing minimum agar. The plates were incubated at $37^{\circ} \mathrm{C}$ for 48 hours, and the His ${ }^{+}$revertant colonies were manually counted.

All experiments were analyzed in triplicate with at least two replicates. A sample was considered to be mutagenic when the number of revertant colonies was at least twice the negative control yield and showed a significant response in analysis of variance. The mutagen used as a positive control was 4-nitro- $O$ phenylenediamine (NPD, $5 \mu \mathrm{g} /$ plate), which is a direct-acting mutagen.

\section{Antimutagenicity test}

The antimutagenic effect of I. lutea extract was assessed using the Ames Salmonella mutagenicity test. The NDP mutagen or 2-aminofluorene (2-AF), which is an indirect-acting mutagen $(5 \mu \mathrm{g} / \mathrm{plate})$, were added to the mixture of I. lutea extract $(0.1,0.2$, and $0.4 \mathrm{mg} / \mathrm{mL})$ and bacterial culture $(0.1 \mathrm{~mL})$ with $\mathrm{S} 9 \mathrm{mix}(0.5 \mathrm{~mL})$. The mutagenicity of each mutagen in the absence of extract is defined as $100 \%$. The number of $\mathrm{His}^{+}$revertants (after subtracting the spontaneous reversions) induced by direct and indirect mutagens tested without extract was considered as $100 \%$. 
The calculation of $\%$ inhibition was done according to the formula given by Ong et al. [14]: \% inhibition $=[1-(\mathrm{T} / \mathrm{M})] / 100$ where $\mathrm{T}$ is the number of revertants per plate in the presence of the mutagen and test sample, and $\mathrm{M}$ is the number of revertants per plate in the positive control. The number of spontaneous revertants was subtracted from the numerator and denominator.

\section{Acute toxicity test}

To assess the acute toxicity of I. lutea extract, a well-established model in the rat was used [15]. This experiment was conducted in accordance with procedures authorized by IIBCE, Montevideo, Uruguay. Male and female (nulliparous and nonpregnant) Sprague-Dawley (SD) rats were approximately 9-10 weeks old on the day of dosing. All animals were housed individually in suspended, stainless steel, wire-mesh cages in animal rooms maintained at a temperature of $18-26^{\circ} \mathrm{C}$, and a relative humidity of $30-70 \%$. Animal rooms were artificially illuminated (fluorescent light) on an approximate 12-hour light/dark cycle. Tap water and pellet feed was available ad libitum except during the fasting period.

Rats were fasted approximately 18 hours prior to dosing. The I. lutea extract was administered to five male and five female rats in a single oral dose by gavage at a dose of $2,000 \mathrm{mg} / \mathrm{kg}$ body weight at a volume of $10 \mathrm{~mL} / \mathrm{kg}$ body weight. Food was returned to the animals approximately three to four hours after dosing. Individual weights were determined at the time of fasting (Day 1), shortly before the test substance was administered (Day 0), and on test days $1,2,4,7$, and 14. The animals were observed for clinical signs of toxicity while handled before and after fasting, once during the first 30 minutes after dosing, at least two more times within four hours after dosing, and daily thereafter. Observations for mortality and signs of illness, injury, or abnormal behaviour were conducted twice daily. Surviving animals were sacrificed and given a complete gross pathology examination.

\section{Results}

Effect of I. lutea extract using the UTI model in the mouse

To investigate the potential preventive effect of the I. lutea extract against UTI, we treated one group of mice daily with I. lutea extract through the oral route, as explained in the Methodology section. $P$. mirabilis CFU recovered from the bladder and kidneys of treated and non-treated animals with the $I$. lutea extract are shown in Figure 1. The number of viable $P$. mirabilis recovered from the kidneys of mice treated with I. lutea was significantly lower than the count recovered from the kidneys of non-treated mice $(P<0.05)$. No significant differences were detected in the bladder CFU of both groups at 0.2 $\mathrm{mg} / \mathrm{mice}$ exposure $(P>0.05)$.

Figure 1. Evaluation of the protection of I. lutea extract against UTI caused by $P$. mirabilis. Data are expressed as $\log _{10}$ CFU per kidneys or bladder. The median (-) is indicated for each group. The range of detection in this assay is $10^{2}$ to $10^{9}$ CFU per kidney or bladder. $P$ values were determined by the Mann-Whitney nonparametric test when comparing the control group (without extract, white dots) and the group treated with the I. lutea extract (black dots).

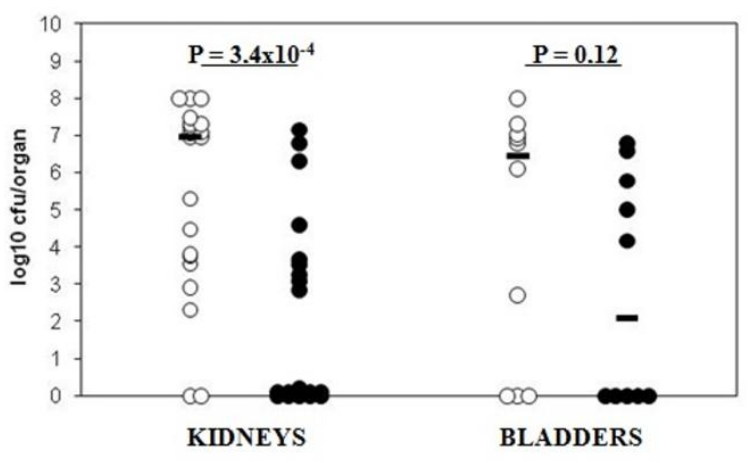


Figure 2. Evaluation of the possible therapeutic effect of $I$. lutea extract against UTI caused by $P$. mirabilis. Data are expressed as $\log _{10}$ CFU per kidneys or bladders. The median (-) is indicated for each group. The range of detection in this assay is $10^{2}$ to $10^{9}$ CFU per kidney or bladder. $P$ values were determined by the Mann-Whitney nonparametric test when comparing the control group (without extract, white) and the group treated (with extract, black) with $0.2 \mathrm{mg} / \mathrm{mouse}$ (Fig. 2A) and 0.5 $\mathrm{mg} /$ mouse (Fig. 2B) of I. lutea extract.

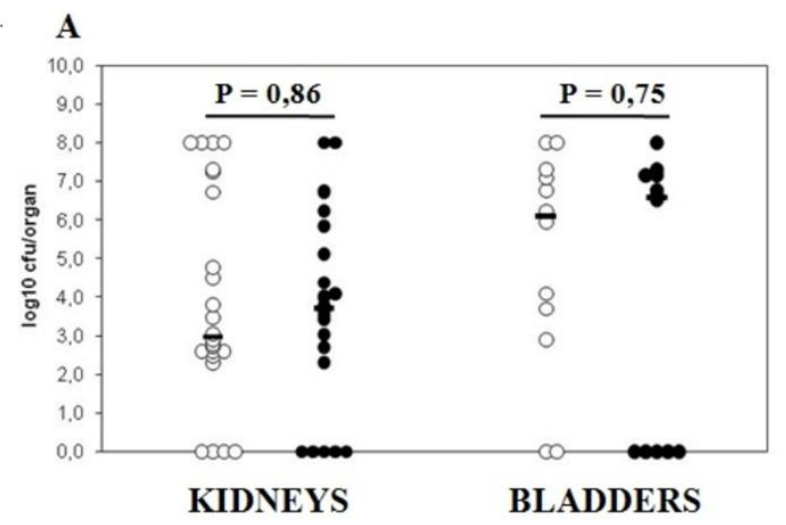

The ability of $I$. lutea extract to treat the mice already challenged with $P$. mirabilis is shown in Figure 2. No significant differences were detected in kidney and bladder bacterial counts of treated and non-treated mice when a $0.2 \mathrm{mg} / \mathrm{mouse}$ I. lutea dose was used $(P>0.05)$; however, a therapeutic effect of I. lutea could be observed when the mice were treated with a $0.5 \mathrm{mg} / \mathrm{mouse}$ extract dose. P. mirabilis $\mathrm{CFU}$ recovered from the kidneys and bladders of treated animals were significantly lower than CFU recovered from the organs of non-treated mice $(P<0.05)$.

Also, the effect of $I$. lutea extract on faecal total aerobic and anaerobic bacteria, LAB, and Enterobacteriaceaeae was assessed. Changes in bacterial counts between the beginning and the end of the administration of I. lutea extract were assessed. Mean CFU of faecal bacteria is shown in Table 1. In general, faecal bacterial count was not affected by $I$. lutea extract consumption $(P>0.05)$.

Table 1. Effect of I. lutea extract on the composition of faecal flora of treated mice. Bacterial counts are expressed as mean $\pm \mathrm{SD} \log _{10} \mathrm{CFU} / \mathrm{gr}$.

\begin{tabular}{|c|c|c|c|c|}
\hline & \multicolumn{4}{|c|}{ Organism } \\
\hline & \begin{tabular}{|l} 
Total \\
aerobes
\end{tabular} & $\begin{array}{l}\text { Total } \\
\text { anaerob }\end{array}$ & LAB & Enterobacteriaceaeae \\
\hline $\begin{array}{l}\text { Pre- } \\
\text { treatment }\end{array}$ & $\begin{array}{ll}9.02 & \pm \\
0.73 & \end{array}$ & $=$ & $\pm\left|\begin{array}{ll}8.67 & \pm \\
0.46 & \end{array}\right|$ & $7.02 \pm 0.72$ \\
\hline $\begin{array}{l}\text { Post- } \\
\text { treatment }\end{array}$ & $\begin{array}{l}9.10 \\
0.15\end{array}$ & $=\begin{array}{l}8.29 \\
0.36\end{array}$ & $\pm \begin{array}{l}8.90 \\
0.22\end{array}$ & $8.01 \pm 0.20$ \\
\hline
\end{tabular}

LAB : Lactic acid bacteria

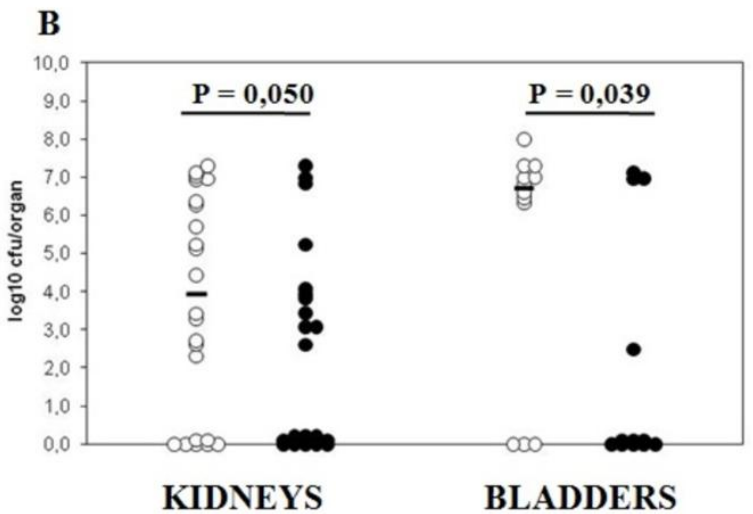

Table 2. Toxicity of I. lutea extract on brine shrimp larvae. Values are showed as the means of three independent experiments

\begin{tabular}{|c|c|c|}
\hline & Concentration & $\begin{array}{l}\text { Larvae mortality } \\
(m, 1\end{array}$ \\
\hline \multirow{5}{*}{ I. lutea } & $0.5 \mathrm{mg} / \mathrm{mL}$ & 3 \\
\hline & $1 \mathrm{mg} / \mathrm{mL}$ & 6 \\
\hline & $2 \mathbf{~ m g} / \mathbf{m L}$ & 6 \\
\hline & $5 \mathrm{mg} / \mathrm{mL}$ & 7 \\
\hline & $10 \mathrm{mg} / \mathrm{mL}$ & 5 \\
\hline \multirow{3}{*}{$\begin{array}{l}\text { Potassium } \\
\text { dichromate } \\
\left(\mathrm{K}_{2} \mathrm{Cr}_{2} \mathrm{O}_{4}\right)\end{array}$} & $12.5 \mathrm{mg} / \mathrm{mL}$ & 53 \\
\hline & $25 \mathrm{mg} / \mathrm{mL}$ & 70 \\
\hline & $50 \mathrm{mg} / \mathrm{mL}$ & 77 \\
\hline
\end{tabular}

\section{Artemia saline test}

The cytotoxic assays were conducted using the Artemia salina lethality test. The results obtained are shown in Table 2. I. lutea extract did not show citotoxic activity at concentration values lower than $10 \mathrm{mg} / \mathrm{mL}$.

\section{Ames test}

The I. lutea extract exhibited a non-toxic effect on $S$. Typhimurium TA98 strain at the dose of 2 $\mathrm{mg} /$ plate $(P>0.05)$.

When the Ames test was used to detect possible mutagenicity of I. lutea extract, the tested sample did not exhibit mutagenic properties on $S$. Typhimurium strain TA98 (Table 3). 
Table 3. Mutagenicity relation of I. lutea extract toward $S$. Typhimurium TA98. Data are means \pm SD of three plates. The number of spontaneous revertants was determined in assays without I. lutea extract. NPD was used as a positive control. The mutagenicity relation was determined according the following formula: mutagenicity relation: $\mathrm{His}^{+}$revertant per plate/His ${ }^{+}$spontaneous revertant.

\begin{tabular}{|l|l|}
\hline I. lutea doses (mg/plate) & $\begin{array}{l}\text { Mutagenicity } \\
\text { relation }\end{array}$ \\
\hline 0.5 & $0.90 \pm 0.22$ \\
\hline 1.0 & $1.04 \pm 0.43$ \\
\hline 2.0 & $1.04 \pm 0.23$ \\
\hline
\end{tabular}

The protective action of $I$. lutea extract against the mutagenicity of NPD and 2-AF was evaluated by the Ames test using $S$. Typhimurium TA98, as presented in Table 4. According to the Ames parameters, when prevention percent ranges between $25-40 \%$, the antimutagenesis effect is considered medium, and when this prevention percentage is higher than $40 \%$, the antimutagenesis effect of the test sample is strong $[16,17]$. In this study, I. lutea extract was able to inhibit the mutagenesis NPD and 2-AF, indicating that the extract showed antimutagenic properties.

\section{Acute toxicity}

When acute toxicity of the I. lutea extract in rats was assessed, all animals gained weight and no adverse clinical signs were observed during the 14 days following oral administration of I. lutea extract at a dose of $2,000 \mathrm{mg} / \mathrm{kg}$ (data not shown). Additionally, no gross lesions were found in any of the organs at necropsy (data not shown). These results demonstrated that $I$. lutea extract was not acutely toxic at $2,000 \mathrm{mg} / \mathrm{kg}$ body weight.
Table 4. Inhibitory effect of I. lutea extract against the mutagenicity of NDP and 2-AF to S. thyphimurium TA98. The calculation of $\%$ inhibition was done according to the formula: $\%$ inhibition $=[1-(\mathrm{T} / \mathrm{M}]) / 100$ where $\mathrm{T}$ is the number of revertants per plate in the presence of mutagen and test sample and $\mathrm{M}$ is the number of revertants per plate in positive control.

\begin{tabular}{|l|l|l|l|}
\hline Mutagen & $\begin{array}{l}\text { I. lutea doses } \\
(\mathbf{m g} / \text { plate })\end{array}$ & $\begin{array}{l}\% \\
\text { Inhibition }\end{array}$ & $\begin{array}{l}\text { Antimutagenic } \\
\text { effect }\end{array}$ \\
\hline \multirow{3}{*}{ NDP } & 0.5 & 6.4 & Weak \\
\cline { 2 - 4 } & 1 & 32.5 & Moderate \\
\cline { 2 - 4 } & 2 & 42.0 & Strong \\
\hline \multirow{3}{*}{$2-\mathrm{AF}$} & 0.1 & 29.0 & Moderate \\
\cline { 2 - 4 } & 0.2 & 49.0 & Strong \\
\cline { 2 - 4 } & 0.4 & 48.0 & Strong \\
\hline
\end{tabular}

\section{Discussion}

UTIs are among the most common infections in humans and represent the most common urologic disease affecting the bladder and kidneys. Traditionally, UTIs are treated with antibacterial drugs, but resistance to these drugs by microorganisms has increased. Recently, the exploitation of wild plants for medicinal purposes has gained acceptance worldwide. The botanical bioactive agents have evolved to protect the plant and therefore may be useful to prevent or treat infections in animals. Because many of these compounds are excreted through the renal system, they could be particularly useful as urinary antiseptics [18].

In a previous work, we studied the effect of $I$. lutea extract on in vitro uropathogenicity of $P$. mirabilis [5]. We observed that I. lutea extract had a significant effect on various attributes associated with $P$. mirabilis urovirulence, including bacterial growth rate, bacterial morphology, swarming differentiation, hemagglutination, and biofilm formation on glass and polystyrene; however, the extract did not exert a significant antibacterial effect.

Complex environmental conditions in vivo, such as osmolarity, $\mathrm{pH}$ and nutrient or substrate availability, differ from those in laboratory cultures [19]. Since environmental conditions affect on bacterial growth, metabolism, and regulation of gene expression, it is necessary to evaluate the effect of antibacterial agents through in vivo approaches after in vitro assays. 
In the present study, we analyzed the effect of the I. lutea extract on UTI in an experimental mouse model. The results demonstrated the effectiveness of the I. lutea extract to prevent UTI in a dose-effect manner.

Previously, we had observed that I. lutea extract had an effect on the mannose-resistant hemagglutination capacity of different $P$. mirabilis strains [5]. According to these results, we hypothesized that the inhibited adherence to erythrocyte receptors indicate that I. lutea could also interfere with renal tissue colonization mediated by adherence to other eukaryotic cell receptors.

A similar situation was seen when epithelial cells from the urinary tract of mice were given cranberry juice and tested for adherence. Over a 14-day period, the mice were given cranberry juice, a product effective in the prevention and management of UTI, instead of water. When compared with control cells, cranberry juice reduced bacterial adhesion by $80 \%$ in mice cell preparations [20]. In addition, it is probable that the extract has a role in affecting other bacterial features related to urovirulence that could be inferred from our previous in vitro results, such as altered growth rate, diminished ability to form biofilms, or affected swarming differentiation.

The intestinal microbiota performs important metabolic and immunological functions and acts as a biological barrier against pathogens. In this study, we evaluated whether the intestinal flora was altered after the supply of I. lutea extract and showed that the numbers of faecal bacteria of treated mice did not change during this study. Kontiokari et al. [21] examined the effect of continuous daily cranberry juice consumption on the normal colonic bacterial flora and no effect was perceptible.

The I. lutea showed no significant toxicity when the brine shrimp test was used. The results found by the brine shrimp assay indicate that the extract has an $\mathrm{LC}_{50}$ value higher than $20 \mu \mathrm{g} / \mathrm{mL}$, the recommended cutoff point for the detection of cytotoxic activity [20]. This means that I. lutea might not be toxic to humans.

The Ames bacterial test done with mutagenic $S$. Typhimurium, has been used with good success to screen mutagenic and antimutagenic properties of different agents [9]. The Ames Salmonella assay has been validated and tested with known mutagens. It has also been shown to work as a mutagenicity assay in different laboratories and yield results comparable to in vivo effects $[22,23]$. In this assay, no mutagenic activity was detected when the I. lutea extract was evaluated, indicating that it is not mutagenic.

I. lutea extract was able to inhibit the mutagenesis of NPD and 2-AF. According to these results, it may be inferred that the extract contains chemical compounds capable of inhibiting the mutagenicity of direct-acting and indirect-acting mutagens. The mechanism by which the antimutagens in the I. lutea extract inhibited the mutagenicity is not known, but we suggest that these antimutagens may interact with some specific enzymes in the liver homogenates that are necessary for the activation of chemical mutagens.

In the present study, the Ames test was also performed to consider an anticancer effect using $S$. Typhimurium. Interestingly, I. lutea extract displayed unexpected antimutagenesis effects.

Oral acute toxicity of I. lutea extract was also evaluated. There was no indication that I. lutea extract was acutely toxic following oral gavage in rats using a 2,000 mg/kg dose. All the rats survived the experiment period and no biologically significant differences in body weights, weight gain, or feed consumption were observed.

The results obtained through in vivo and in vitro approaches suggest that $I$. lutea extract might represent an interesting new strategy to prevent or treat UTI, if consumed orally.

\section{Acknowledgments}

This work was supported by FCE 064/2006 (DICYT), PEDECIBA (Uruguay) and AMSUD-Pasteur Program. We thank Álvaro Vázquez for contributing to the scientific discussion, Professor Mario Piaggio for his help in plant identification, and Maria Inés Isla and Catiana Zampini for technical support.

This study was performed according to the academic code of ethics. The contents are solely the responsibility of the authors and do not necessarily represent the views of the funding agencies.

\section{References}

1. Krieger JN (2002) Urinary Tract Infections: What's New? J Urol 168: 413-419.

2. Johnson DE, Russell RG, Lockatell CV, Zulty JC, Warren JW, Mobley HL (1993) Contribution of Proteus mirabilis urease to persistence, urolithiasis, and acute pyelonephritis in a mouse model of ascending urinary tract infection. Infect Immun 61: 2748-2754.

3. Streit JM, Fritsche TR, Sader HS, Jones R (2004) Worldwide assessment of dalbavancin activity and spectrum against over 6,000 clinical isolates. Diagn Microbiol Infect Dis 48: 137-143.

4. Coates A, Hu Y, Bax R, Page C (2002) The future challenges facing the development of new antimicrobial drugs. Nat Rev Drug Discov 1: 895-901. 
5. Sosa V, Zunino P (2009) Effect of Ibicella lutea on uropathogenic Proteus mirabilis growth, virulence, and biofilm formation. J Infect Dev Ctries 3: 762-770.

6. Corpet DE, Lumeau S (1987) Antibiotic residues and Rplasmid selection: are in vitro methods good models? Zentralbl Bakteriol Mikrobiol Hyg 264: 178-184.

7. Sugimura $T$ (2000) Nutrition and dietary carcinogens. Carcinogenesis 21: 387-395.

8. Zunino P, Geymonat L, Allen AG, Legnani-Fajardo C, Maskell DJ (2000) Virulence of a Proteus mirabilis ATF isogenic mutant in not impaired in a mouse model of ascending urinary tract infection. FEMS Immunol Med Microbiol 29: 137-144.

9. Maron DM, Ames BN (1983) Revised methods for Salmonella mutagenicity test. Mutat Res 113: 173-215.

10. Hagberg L, Engberg Y, Freter R, Lane J, Olling S, Svanborg-Eden D (1983) Ascending unobstructed urinary tract infection in mice caused by pyelonephritogenic Escherichia coli of human origin. Infect Immun 40: 273283.

11. Butel MJ, Roland N, Hibert A, Popot F, Favre A, Tessèdre AC, Bensaada M, Rimbault A, Szylit O (1998) Clostridial pathogenicity in experimental necrotising enterocolitis in gnotobiotic quails and protective role of bifidobacteria. $\mathrm{J}$ Med Microbiol 47: 391-399.

12. Meyer BN, Ferrigni NR, Putnam JE, Jacobsen LB, Nichols DE, McLaughlin JL (1982) Brine shrimp: a convenient general bioassay for active plants constituents. Planta Med 45: 31-34.

13. Yen GC, Chen HY, Peng HH (2001) Evaluation of the cytotoxicity, mutagenicity and antimutagenicity of emerging edible plants. Food Chem Toxicol 39: 1045-1053.

14. Ong TM, Whong WZ, Stewart J, Brockman HE (1986) Chlorophyllin: a potent antimutagen against environmental and dietary complex mixtures. Mutat Res 173: 111-115.

15. Organization for Economic Cooperation and Development (2000) OECD guidelines for the testing of chemicals: Revised draft guideline. Acute Oral Toxicity. p 423.
16. Ames BN, Lee FD, Durston WE (1973) An improved bacterial test system for the detection and classification of mutagens and carcinogens. Proc Natl Acad Sci (USA). 70: 782-786.

17. Ames BN, Mccann J, Yamasaki E (1975) Methods for detecting carcinogens and mutagens with the Salmonella/mammalian-microsome mutagenicity test. Mutat Res. 31: 347-64.

18. Yarnell E (2002) Botanical medicines for the urinary tract. World J Urol 20: 285-293.

19. Smith H (2000) Questions about the behavior of bacterial pathogens in vivo. Phil Trans R Soc Lond 355: 551-564.

20. Sabota AE (1984) Inhibition of bacterial adherence by cranberry juice: potential use for the treatment of urinary tract infections. J Urol 131: 563-568.

21. Kontiokari T, Salo J, Eerola E, Uhari M (2005) Cranberry juice and bacterial colonization in children: a placebocontrolled randomized trial. Clin Nutr 24: 1065-72.

22. Geran RI, Greenberg HM, McDonald M, Abbott BJ (1972) Protocols for screening chemical agents and natural products against animal tumors and other biological systems. Cancer Chemoth Rep 33: 1-17.

23. Eisenbrand G, Pool-Zobel B, Baker V, Balls M, Blaauboer BJ, Boobis A, Carere A, Kevekordes S, Lhuguenot JC, Pieters R, Kleiner J (2002) Methods of in vitro toxicology. Food Chem Toxicol 40: 193-236.

\section{Corresponding author}

Dr. Pablo Zunino

Avenida Italia 3318

CP11600 Montevideo, Uruguay

Tel.: +598 (2) 4871616, fax: +598 (2) 4875548

Email: pablo@iibce.edu.uy

Conflict of interests: No conflict of interests is declared. 